\title{
P-10
}

\section{Use of Medicinal Flora Enlisted IN Quran And Ahadith by Malaysian Oncology Patients}

\author{
Maryam Farooqui ${ }^{1, *}$, Azmi Hassali ${ }^{2}$, Aishah Knight ${ }^{3}$, Asrul Akmal $^{2}$, Aslam Farooqui ${ }^{4}$, Mahibub \\ Kanakal $^{1}$, Fahad Saleem ${ }^{2}$, Noman ul $\mathrm{Haq}^{2}$ and Humera $\mathrm{Naz}^{5}$ \\ ${ }^{1}$ Faculty of Pharmacy, Universiti Teknologi MARA, Bertam Campus, Kepala Batas, 13200, Penang, Malaysia; \\ ${ }^{2}$ Discipline of Social \& Administrative Pharmacy, Universiti Sains Malaysia, 11800, Penang, Malaysia; ${ }^{3}$ Advanced \\ Medical and Dental Institute, Universiti Sains Malaysia, Kepala Batas, 13200, Penang, Malaysia; ${ }^{4}$ Department of \\ Medicine, Allianze University College of Medical Sciences, 13200, Penang, Malaysia; ${ }^{5}$ Faculty of Pharmacy, Universiti \\ Teknologi MARA, Puncak Alam Campus, 42300, Bandar Puncak Alam; E-mail: maryam089@ppinang.uitm.edu.my
}

The use of Traditional and Complementary medicines (T\&CM) is common among healthy individuals as well as patients with chronic disease including cancer. Use of herbal medicines are common among cancer patients due to an easy access and perceived simplicity with less or no side effects. The medicinal properties of many herbs are well documented in Quran and Ahadith, however; prevalence of these herbal plants by Malaysian cancer patients is not explored completely. The study examines the use of medicinal flora enlisted in Quran and Ahadith by Malaysian oncology patients. The study was designed as a questionnaire based, cross sectional analysis. The data was collected between August to November 2011 among 184 cancer patients using self administered questionnaire at Penang General Hospital. One hundred and thirty four (72.8\%) patients reported using herbal and dietary supplements. Honey, grapes, mushroom, garlic, barely, dates, olives and ginger were commonly used by the patients either in raw form or commercially available products. The herbs were than searched systematically from Al-Quran and authentic Ahadith' books for their medicinal properties. The Muslim scriptures support the medicinal importance of these plants, however; the therapeutic and curative significance is not well established for cancer care. Since oncology patients are reported to use these herbs after the cancer diagnosis, and the medicinal properties are evident from Quran and Ahadith, recommendations can be made to further investigate the safety and efficacy of these herbs for cancer care.

Keywords: Herbs, Quran, Ahadith, Cancer patients, Malaysia. 